\title{
Percepção e comportamento ambiental de consumidores de combustíveis em um auto posto na cidade de São Paulo-SP
}

\section{Perception and environmental behavior of fuel consumers in an auto service station in the city of São Paulo-SP}

Percepción y comportamiento ambiental de consumidores de combustibles en un puesto de gasolina en la ciudad de São Paulo-SP

Jefferson S. Tavares

Aluno, UNINOVE, Brasil. tavjefferson@yahoo.com.br

Heidy Rodriguez Ramos Professora Doutora, UNINOVE, Brasil. heidyrr@uni9.pro.br

Ana Paula do Nascimento Lamano-Ferreira Professora Doutora, UNINOVE, Brasil. ana_paula@uni9.pro.br 


\section{RESUMO}

A poluição atmosférica é considerada uma questão de saúde pública visto que causa efeitos muitas vezes irreversíveis à saúde humana. Dentre as possíveis causas se destaca, principalmente, a emissão de poluentes gerados por veículos que circulam nos grandes centros urbanos. O presente artigo tem por objetivo analisar a percepção e os comportamentos de compra de consumidores de combustíveis na região metropolitana de São Paulo-SP. Cabe destacar que apesar do tema "Percepção e comportamento de consumidores de combustíveis" não ser recorrente na literatura, encontrou-se duas vertentes, a de consumo verde e comportamento pró-ambiental, que embasam em seu entendimento na liberdade de escolha. Buscou-se, demonstrar, por meio da conceituação de autores e de evidências de pesquisa empíricas, a possibilidade do consumo consciente de combustíveis além do fator monetário. Tratasse de um estudo qualitativo. $O$ instrumento utilizado para a coleta dos dados foi um questionário composto por questões fechadas e considerou uma escala Likert de 0 a 10 pontos, objetivando conhecer o perfil socioeconômico do entrevistado, a percepção ambiental, os hábitos de consumo e as motivações em relação ao uso do veículo. A partir dos resultados da coleta de dados, é possível tecer algumas considerações sobre o tema deste estudo. Pode-se concluir que indivíduos que tem consciência do impacto causado por sua escolha na hora de abastecer seu veículo, tendem a aderir comportamentos conscientes de consumo, porém, o fator preço é decisivo na escolha do combustível.

PALAVRAS-CHAVE: Comportamento ambiental, Valores humanos, Percepção ambiental

\section{ABSTRACT}

Air pollution is considered a public health issue since it causes effects that are often irreversible to human health. Among the possible causes, the emission of pollutants generated by vehicles that circulate in large urban centers stands out. The purpose of this article is to analyze the perceptions and behavior of consumers purchasing fuels in the São Paulo metropolitan region. It should be noted that although the theme "Perception and behavior of fuel consumers" is not recurrent in the literature, two aspects were found: green consumption and pro-environmental behavior, which are based on their understanding of freedom of choice. We sought to demonstrate, through the conceptualization of authors and empirical evidence of research, the possibility of conscious consumption of fuels beyond the monetary factor. It was a qualitative study. The instrument used to collect the data was a questionnaire composed of closed questions and considered a Likert scale of 0 to 10 points, aiming to know the socioeconomic profile of the interviewee, the environmental perception, consumption habits and motivations in relation to the use of the vehicle. From the results of the data collection, it is possible to make some considerations about the theme of this study. It can be concluded that individuals who are aware of the impact caused by their choice when fueling their vehicle tend to adhere to consumer-conscious behavior, but the price factor is decisive in the choice of fuel.

KEYWORDS: Environmental behavior, Human values, Environmental perception

\section{RESUMEN}

La contaminación atmosférica es considerada una cuestión de salud pública una vez que causa efectos muchas veces irreversibles a la salud humana. Entre las posibles causas se destaca, principalmente, la emisión de contaminantes generados por vehículos que circulan en los grandes centros urbanos. El presente artículo tiene por objetivo analizar la percepción y los comportamientos de compra de consumidores de combustibles en la región metropolitana de São Paulo-SP. Cabe destacar que a pesar del tema "Percepción y comportamiento de consumidores de combustibles" no ser recurrente en la literatura, fueron encontradas dos vertientes, la del consumo verde y la del comportamiento proambiental. Se procuró demonstrar, por medio de la definición de autores y de evidencias de investigación empíricas, la posibilidad del consumo consciente de combustibles, además del factor monetario. Fue realizado un estudio cualitativo. El instrumento utilizado para la recolecta de los datos fue una encuesta compuesta por preguntas cerradas y consideró una escala Likert de 0 a 10 puntos, con el objetivo de conocer el perfil socioeconómico del entrevistado, su percepción ambiental, los hábitos de consumo y las motivaciones en relación al uso del vehículo. A partir de los resultados de la recopilación de los datos, es posible elaborar algunas consideraciones sobre el tema de este estudio. Se pude concluir que los individuos que tienen consciencia del impacto causado por su elección a la hora de abastecer su vehículo, tienden a adherir comportamientos conscientes de consumo, sin embargo, el factor precio es decisivo en la elección del combustible.

PALABRAS CLAVE: Comportamiento ambiental, Valores humanos, Percepción ambiental.

\section{INTRODUÇÃO}

Assuntos relacionados à sustentabilidade ganham espaço na mídia e fomentam debates quanto ao futuro do planeta e preocupações com o meio ambiente nas últimas décadas. Os efeitos 
desta "preocupação" têm alcançado as esferas políticas, econômico-social, ético e individual. Crianças são incentivadas a plantarem árvores, adultos a economizar recursos naturais e reciclar. Além disso, empresas esforçando-se em disseminar a imagem de "ambientalmente responsáveis" para garantir e atrair um novo público consciente. Entretanto, o crescente aumento no consumo necessário para movimentar a economia gerando emprego e renda não condiz com todo este discurso, visto que promove prejuízos ao meio ambiente ocasionados pelo sistema produtivo e resíduos pós-consumo, como descarte de produtos, embalagens e outros (GORNI et al., 2016).

A sociedade contemporânea ainda é definida como uma sociedade de consumo e, mais ainda, nela, o hedonismo, filosofia que considera o prazer como um bem, aparece como meta a ser alcançada e o consumo é um dos principais meios para tal (OLIVEIRA; SANTOS, 2016). Segundo Gorni et al., (2016) inicialmente, as pessoas buscavam descobrir as principais causas dos problemas ambientais. Posteriormente, os consumidores tornaram-se conscientes, e com isso, percebem a necessidade de fazer escolhas mais responsáveis e começam a olhar de forma diferenciada para as instituições e corporações que também se comportam desta maneira. Os consumidores estão conscientes de que a proteção ambiental não é apenas tarefa de empresas e instituições, mas também deles, e por tanto, começam a escolher determinados produtos, em vez de outros (STERN, 1997). Estes produtos são chamados de "ecologicamente corretos" e como exemplos podem ser citados os alimentos e bens de consumo duráveis como automóveis que indiretamente é o nosso objeto de estudo.

O problema da poluição atmosférica, nas grandes metrópoles, tem-se constituído numa das mais graves ameaças, o que serve de alerta para as autoridades e órgãos competentes, pois estão intimamente relacionadas à qualidade de vida dos habitantes dos grandes centros. Sabese que o veículo tem grande parcela nas emissões de gases e carregam diversas substâncias tóxicas que, em contato com o sistema respiratório, podem produzir vários efeitos negativos sobre a saúde. Essa emissão é composta de gases como: monóxido de carbono (CO), óxidos de nitrogênio (NOx), hidrocarbonetos (HC), óxidos de enxofre (Sox), material particulado (MP), etc. Em seu Relatório de Emissões Veiculares a Companhia Ambiental do estado de São Paulo (CETESB), divulga que o Estado de São Paulo enfrenta uma situação particularmente preocupante por deter grande parte da frota automotiva do país (CETESB, 2013).

Dados divulgados em 2017 pela Associação Nacional dos Fabricantes de Veículos Automotores (ANFAVEA) em seu anuário relatam que cerca de 34,5\% dos automóveis estão da cidade de São Paulo-SP. Mostram também que em 1957, quando começou a ser dimensionada a produção de automóveis, era de 10.449 unidades e em 2015 passou dos 2 milhões de unidades com destaque para o ano de 2013 onde alcançou a produção recorde de mais de 2,9 milhões de unidades. No entanto, apenas a partir do ano de 2003 é que começaram a ser fabricados os veículos flex fuel no país.

Motores flex fuel possuem um sensor que detecta e faz o reconhecimento do teor de oxigênio do combustível, identificando assim a presença do etanol, (BIODIESELBR, 2006). A informação é passada para a unidade de comando que de forma automática altera todas as funções de gerenciamento do motor ao combustível utilizado. O motor bicombustível dá ampla liberdade de escolha para os usuários. Eles podem escolher entre gasolina e etanol, de acordo com o desempenho que pretendem do veículo. Outra variável importante é que o sistema permite 
levar em conta o dinheiro gasto ao abastecer o carro, já que o usuário pode escolher depois de calcular a relação de preços na bomba entre o etanol e a gasolina, e economizar com isto. Para Luiz Carlos Corrêa Carvalho, presidente da Câmara Setorial de Açúcar e Álcool, "o consumidor passa a ser o rei do negócio", afirma ele (BIODIESELBR, 2006).

\section{OBJETIVO}

\subsection{OBJETIVO GERAL}

Diante do crescimento da frota e considerando a possibilidade de escolha do tipo de combustível a ser utilizado, esta pesquisa tem como objetivo analisar a percepção e os comportamentos de compra de consumidores de combustíveis na região metropolitana de São Paulo-SP.

\subsection{OBJETIVOS ESPECÍFICOS:}

- Caracterizar o perfil socioambiental dos respondentes.

- Analisar as motivações em relação ao uso do veículo e consumo de combustíveis.

- Analisar a percepção ambiental dos consumidores e o impacto que sua escolha tem no meio ambiente.

- Analisar o comportamento e intenção de compra de produtos menos agressivos ao meio ambiente.

\section{REFERENCIAL TEÓRICO}

\subsection{COMPORTAMENTO E PERCEPÇÃO AMBIENTAL DE CONSUMIDORES}

Segundo Stern (1999) é possível dividir o comportamento ambientalmente responsável em três domínios de influência: domínio pessoal, comportamental e contextual. 0 domínio pessoal representa os valores básicos do indivíduo, sua percepção como parte integrante do ecossistema, ou seja, a relação homem e meio ambiente, as consequências ambientais que ameaçam seus interesses e a sua responsabilidade para corrigir essas consequências visando reduzir as ameaças. Os valores básicos dos indivíduos podem ser entendidos como: biosféricos, a decisão de agir próambientalmente considerando custos e benefícios à natureza; altruístas, quando a decisão de agir em prol do meio ambiente está baseada nos custos e benefícios percebidos por seus pares; e egoístas, que consideram os custos e benefícios do comportamento ambientalmente correto, vão além de valores e crenças. Ética e valores pessoais surgem representando a obrigação moral de adotar um comportamento ambientalmente correto, conforme a teoria de valor-crença-norma.

Em seu estudo, Casali (2011), por sua vez, identificou quatro categorias de Responsabilidade Social do Consumidor: Comportamento altruísta, Comportamento ambientalmente sustentável, Comportamento ativista e Comportamento ético na relação de troca. Gonçalves e Nascimento (2000) observaram que surgia no final do século passado uma nova área no interesse da sociedade com relação às questões ambientais, a qualidade e as condições de vida dos homens na terra, obrigando-os a realizarem rápidas e intensas transformações comportamentais.

No que diz respeito a comportamentos ambientalmente corretos estão fortemente relacionados a algum tipo de sacrifício monetário (investimento) ou não monetário (tempo e esforço). A consciência ambiental está relacionada ao valor que cada indivíduo 
está disposto a investir em produtos ecologicamente corretos e ao quanto acreditam que esses produtos podem impactar no seu bem-estar (TONI et al.,2012).

Produtos ecologicamente corretos podem custar mais, e reciclar produtos pode levar mais tempo e esforço. Por outro lado, isso pode provocar uma satisfação maior (benefício) para o cliente, o que irá compensar seu sacrifício. Pickett-Baker e Ozaki (2008) apresentam que os valores relacionados às questões pró-ambientais não garantem comportamentos pró- ambiental no que se refere escolha de produtos. Valores pró-ambientais têm mais probabilidade de resultar em comportamento próambiental quando os valores e convicções são específicos, palpáveis, recompensadores e atendam seus interesses pessoais.

Desta forma, a preocupação com a sustentabilidade ganha força nos mais diversos setores produtivos ao redor do mundo. Produtos de origem artesanal ou industrializados, de uso pessoal, alimentos, uso doméstico ou comercial, agrícola e industrial, que sejam não sejam tóxicos e notadamente benéficos ao meio ambiente e a saúde, são denominados de produtos "verdes" e se multiplicaram, favorecendo desenvolvimento de um modelo econômico socioambiental (IDHEA, 2012).

\subsection{HOMEM X MEIO AMBIENTE}

Considerando os aspectos sociais e ecológicos trazidos pelo consumismo, é preciso mudar intencionalmente e quebrar os paradigmas culturais em que as normas, símbolos, valores e tradições estimulem o consumo sustentável para a satisfação do bem-estar do ser humano, em conjunto com práticas que canalizem direcionam a energia humana para práticas que ajudem a recuperar o bem-estar do planeta (GORNI et al., 2016). Para Portilho (2005), cada indivíduo deve sentir-se responsável por suas ações e as escolhas motivadas por preocupações ambientais para serem encaradas como essenciais.

Andrés e Salinas (2002) verificaram que os indivíduos com um afeto ambiental (consciência ecológica maior) teriam uma atitude ecológica mais forte. Ou seja, aqueles indivíduos que são mais informados e tem uma opinião formada sobre o assunto, tendem a ter uma atitude de compra diferenciada de outra pessoa que não que tem o mesmo conhecimento. Segundo esses autores, os indivíduos com um maior grau de afeto ambiental (consciência ecológica) possuem uma maior intenção de comportamento ecológico, podendo este se manifestar de diversas formas, não se relacionando apenas ao comportamento de compra, Queiroz et al. (2009) partilham deste princípio e consideram que as pessoas compram determinado produto pelo tipo de informação que possuem sobre ele. Caso não seja fornecida esta informação, o consumidor não pensará sobre o assunto, podendo comprar o que achar interessante, priorizando muitas vezes o preço do produto. Por isso, é importante que haja uma conscientização para que a população venha a contribuir com o meio em que vive.

\subsection{POLUIÇÃO ATMOSFÉRICA}

Normalmente relacionamos a poluição atmosférica a três fatores a primeira e a emissão de poluentes por fontes antropogênicas ou naturais, seguindo para o processo de dispersão dos poluentes, no qual é transportado pelos movimentos do ar e por fim as precipitações desencadeadas pelas massas de ar. O grau de qualidade do ar e definido através da interação 
entre os gases poluentes e a atmosfera, isto é quanto maior a concentração de gases poluentes, pior, ou melhor, será a classificação da qualidade do ar (FERREIRA; OLIVEIRA, 2016).

Pesquisas relacionadas ao consumo verde vêm aumentando a cada dia e questões relacionadas à sustentabilidade cada vez mais em pauta em busca do consenso, entre o público, em geral, de que algo precisa ser feito para preservar o ambiente e diminuir as mudanças no clima (KOLLER et al., 2011). Martins (1996) afirma que, alterações ambientais causadas por processos antrópicos resultam em fenômenos chamados de "ilha de calor", responsáveis por temperaturas mais elevadas na área central da cidade. Devido a pluviosidades quantitativamente maiores nas áreas urbanizadas, e inversão térmica, associada a períodos de estabilidade atmosférica, principalmente no inverno.

Cruz (2006) segue o mesmo raciocínio, atribui e alerta que o crescimento contínuo do número de veículos que circulam nas vias de tráfego das cidades pode gerar impactos negativos, tais como congestionamentos, acidentes de trânsito, degradação da paisagem, degradação da qualidade de vida, utilização de espaços públicos prioritariamente por veículos, desconforto geral no uso dos espaços públicos pelo pedestre, poluição sonora, poluição atmosférica e doenças respiratórias. Segundo a Organização Mundial da Saúde (OMS), cerca de 2 milhões de pessoas morrem no mundo devido à má qualidade do ar causada por poluição.

A Organização Mundial da Saúde (OMS) chegou a esta conclusão analisando dados de 1.100 cidades, de 91 países, com mais de 100 mil habitantes. De acordo com seus especialistas, a contaminação do ar pode levar a problemas cardíacos e respiratórios. Em 2008 de acordo com a OMS cerca de 1,34 milhão de pessoas morreram prematuramente por causa dos efeitos da poluição sobre a saúde, apontam que políticas de prevenção podem mitigar tais as mortes, ressaltam também que a poluição do ar é provocada por vários fatores, como os gases de escapamentos dos veículos, a fumaça de fábricas e fuligem das usinas infelizmente ainda não são todos os países ou estados que possuem regulamentação sobre a qualidade do ar (BRASIL, 2011).

\subsection{CRESCIMENTO DA FROTA DE VEÍCULOS}

Segundo a Associação Nacional dos Fabricantes de Veículos Automotores (ANFAVEA), dados divulgados em seu anuário em 2017, o setor automotivo está presente em todas as regiões brasileiras com 64 unidades industriais responsáveis por grande geração de renda e emprego. A indústria mudou significativamente a vida das pessoas neste período: em 1957 empregava 9,8 mil funcionários e gerava 140 mil empregos diretos e indiretos (ANFAVEA, 2017).

O cenário mudou muito e apesar de toda a tecnologia aplicada no setor, atualmente são mais de 140 mil colaboradores diretos e 1,5 milhão de empregos na cadeia produtiva. Em 1957 quando começou a ser dimensionada a produção de automóveis, era de 10.449 unidades e em 2016 passou de 1,9 milhões de unidades com destaque para o ano de 2013 onde alcançou a produção recorde de mais de 2,9 milhões de unidades. E não foi somente no âmbito fabril que a indústria automobilística mudou o cenário local. O setor investiu fortemente em engenharia e pesquisa e foi responsável por inúmeras inovações, dentre elas o carro movido a etanol, que teve início em 1975, quando o Governo Federal criou o Programa Nacional do Álcool (PROÁLCOOL). 


\section{Periódica Eletronica}

\section{Fórum Ambiental}

A experiência adquirida com o Proálcool possibilitou a criação, em 2003, da tecnologia flex, solução de uso de combustível renovável no mundo.

Neste mesmo anuário, a ANFAVEA relata que cerca de $26,8 \%$ dos automóveis foram licenciados na cidade de São Paulo-SP, conforme ilustrado na figura 1.

Figura 1: Participação percentual no licenciamento de automóveis nos 5 maiores estados consumidores 2000/2016.

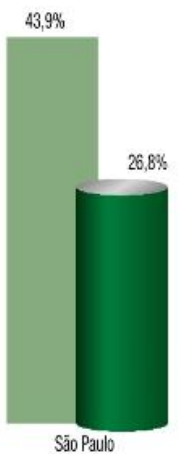

FONTE: ANFAVEA (2017)

\section{Total Brasil / Total Brazil}

$2000 \quad 1.489 .481$

$2016 \quad 2.050 .321$
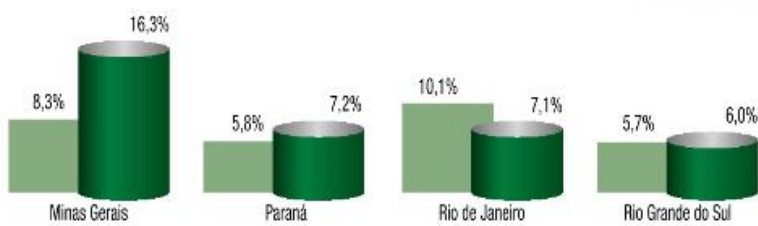

Porem, a partir do ano de 2003 é que começaram a ser fabricados os veículos flex no país com tímidos 39.095 exemplares e um crescimento exponencial em relação aos outros combustíveis ao longo dos anos evidenciado na Figura 2.

Figura 2: Produção de automóveis novos leves por combustível- 2003/2016

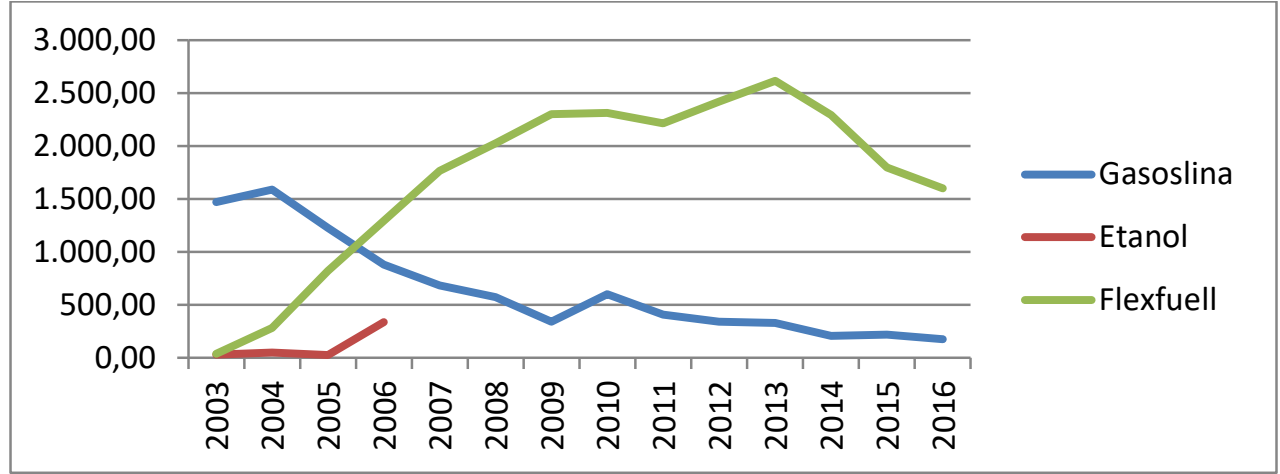

FONTE: AMFAVEA, 2017

\section{METODOLOGIA}

Este estudo caracteriza-se por ser exploratório, com abordagem qualitativa. Tratasse de estudo comparativo entre a percepção e o comportamento ambientalmente responsável de consumo buscando relacioná-lo com alguns parâmetros como: escolaridade, gênero e idade por meio de questionário respondido por proprietários de veículos flex em um auto posto na cidade de São Paulo-SP. Segundo Gil (2006), esse tipo de investigação tem como objetivo desenvolver, esclarecer ou modificar conceitos e ideias, tendo em vista a formulação mais precisa de problemas ou hipóteses pesquisáveis para estudos futuros.

Para obtermos informações que tragam suporte e fundamentação ao estudo, bem como fornecer condições para inferir e formular conclusões, foi utilizado como técnica e instrumentos 


\section{Periódica Eletrônica}

\section{Fórum Ambiental}

Volume 14, Número 1, 2018

ISSN 1980-0827

\section{da Alta Paulista}

de pesquisas, o levantamento bibliográfico sobre a temática efetuada em arquivos de artigos reunidos em periódicos internacionais e nacionais, na internet, em dissertações, em teses acadêmicas e em livros técnicos que tratam da temática, além da aplicação de questionário.

O instrumento utilizado para a coleta dos dados foi um questionário composto por questões fechadas, constituído de quatro seções descritas no quadro 1.

\section{Quadro 1: Questões do instrumento de pesquisa}

\begin{tabular}{|c|c|c|}
\hline Seções & Objetivos Específicos & Perguntas \\
\hline $\begin{array}{c}\text { Perfil } \\
\text { socioambiental }\end{array}$ & $\begin{array}{l}\text { Caracterizar o perfil } \\
\text { socioambiental dos } \\
\text { respondentes }\end{array}$ & $\begin{array}{l}\text { 1. Nome } \\
\text { 2. Idade } \\
\text { 3. Escolaridade } \\
\text { 4. Gênero (M) (F) } \\
\text { 5. Renda familiar mensal: }\end{array}$ \\
\hline $\begin{array}{l}\text { Uso do veículo e } \\
\text { opção de } \\
\text { combustíveis }\end{array}$ & $\begin{array}{l}\text { Analisar as motivações } \\
\text { em relação ao uso do } \\
\text { veículo e consumo de } \\
\text { combustíveis }\end{array}$ & $\begin{array}{l}\text { 6. Exerce alguma atividade remunerada com o veículo? } \\
\text { ( ) Sim ( ) Não } \\
\text { 7. Quantas vezes por semana utiliza seu veículo? } \\
\text { ( ) De uma à três vezes ( ) De segunda à sexta ( ) Finais de semana e } \\
\text { feriados ( ) Todos os dias } \\
\text { 8. Quando você abastece com etanol? } \\
\text { ( ) sempre } \\
\text { ( ) quando está mais barato } \\
\text { ( ) nunca } \\
\text { ( ) outro } \\
\text { 9. Minha escolha baseia-se em: } \\
\text { ( ) Autonomia } \\
\text { ( ) Preço } \\
\text { ( ) Meio ambiente } \\
\text { ( ) Outro } \\
\text { 10. Você utiliza transporte público? ( ) sim ( ) não } \\
\text { () De uma à três vezes ( ) De segunda à sexta ( ) Finais de semana e } \\
\text { Feriados ( ) No dia de Rodizio do veiculo }\end{array}$ \\
\hline $\begin{array}{l}\text { Percepção } \\
\text { Ambiental }\end{array}$ & $\begin{array}{l}\text { Analisar a percepção } \\
\text { ambiental dos } \\
\text { consumidores e o } \\
\text { impacto que sua } \\
\text { escolha tem no meio } \\
\text { ambiente }\end{array}$ & $\begin{array}{l}\text { Abaixo está uma lista de afirmações sobre percepção e comportamentos, } \\
\text { ligados ao meio ambiente onde } \mathbf{0} \text { é discorda totalmente e } 10 \text { concorda } \\
\text { totalmente. } \\
\text { 11.Os combustíveis fósseis geram mais } \mathrm{CO}_{2} \text {, e aumentam o aquecimento } \\
\text { global. } \\
\text { 12. Eu compraria um automóvel elétrico, pois emite menos gases de efeito } \\
\text { estufa. } \\
\text { 13. As baterias têm em sua composição metais pesados, que são tóxicos, } \\
\text { podendo trazer danos se descartados inadequadamente. } \\
\text { 14. A queima do álcool emite menos gases poluentes na atmosfera. } \\
\text { 15. Percebi melhora na qualidade do ar na cidade de São Paulo. } \\
\text { 16.Converso com amigos vizinhos e parentes sobre questões ambientais. } \\
\text { 17. O uso de automóveis prejudica a qualidade do ar. } \\
\text { 18. Os seres humanos têm o direito de modificar o ambiente natural para } \\
\text { atender às suas necessidades. }\end{array}$ \\
\hline $\begin{array}{l}\text { Comportament } \\
\text { o } \\
\text { Ambiental }\end{array}$ & $\begin{array}{c}\text { Analisar o } \\
\text { comportamento e } \\
\text { intenção de compra de } \\
\text { produtos menos } \\
\text { agressivos ao meio } \\
\text { ambiente }\end{array}$ & $\begin{array}{l}\text { 19. Escolho abastecer meu veículo com etanol porque polui menos que a } \\
\text { gasolina o meio ambiente. } \\
\text { 20. Escolho abastecer meu veículo com etanol porque é mais barato. } \\
\text { 21. Utilizo transporte público para ajudar o meio ambiente. }\end{array}$ \\
\hline
\end{tabular}

Fonte: Elaborado pelos autores (2017)

\section{ANÁLISE DOS RESULTADOS}


O questionário foi aplicado no dia 26 de novembro de 2016 em um auto posto localizado a margem do rio Tiete na cidade de São Paulo no bairro do Pari. No período de pesquisa foram abordados 19 motoristas durante o abastecimento, apenas 10 concordaram em responder 0 questionário e 8 foram preenchidos corretamente. Segue a análise considerando os objetivos específicos definidos no estudo.

A partir dos dados da amostra analisada, percebeu-se que $88 \%$ dos respondentes são homens e apenas $12 \%$ mulheres. A totalidade da amostra apresentara um grau de instrução entre 10 e 2응 Grau. A maior concentração de respondentes tem idade entre 25 e 38 anos. Quanto à renda familiar da amostra, foi obtida uma concentração maior tem familiar entre $R \$ 1000$ e $R \$ 3000$, $50 \%$ dos respondentes estão nesta faixa. Traçado o perfil sócio econômico, na etapa seguinte foi avaliado o uso do veículo e a motivação na escolha do tipo de combustível. Os dados mostram que:

- Nenhum dos respondentes utiliza o veículo para atividade remunerada.

- $50 \%$ dos respondentes declaram o uso do veículo todos os dias da semana $25 \%$ de uma a três vezes e $25 \%$ se dividem entre o período de segunda a sexta e finais de semana apenas.

- Apenas um respondente admite o uso de transporte público.

- $63 \%$ dos respondentes, informaram que sempre abastecem com etanol.

- $37 \%$ considera a variável preço como relevante na escolha do combustível mais barato. Em resumo, dos respondentes, $63 \%$ declararam que sua escolha está baseada no preço e $37 \%$ na autonomia.

Analisando a Tabela 1 pode-se observar uma maior concentração de respostas entre 8 e 10 pontos na escala, o que nos leva à conclusão que os consumidores de combustíveis pesquisados tem grande percepção dos aspectos relacionados ao meio ambiente e uso de combustíveis menos poluentes. Por outro lado, especificamente a variável "Percebi melhora na qualidade do ar na cidade de São Paulo" é a que concentra uma maior quantidade de respostas entre 0 e 2 pontos na escala, demonstrando que os respondentes discordaram da afirmação dessa variável.

Tabela 1: Quantidade de respostas por variável de percepção ambiental, onde 0 é discorda totalmente e 10 concorda totalmente.

\begin{tabular}{|c|c|c|c|c|}
\hline \multirow{2}{*}{$\begin{array}{l}\text { Variável de percepção ambiental } \\
\text { Os combustíveis fósseis geram mais } \mathrm{CO} 2 \text {, e aumentam o aquecimento global. }\end{array}$} & \multicolumn{4}{|c|}{01234678910} \\
\hline & 1 & 1 & 22 & 2 \\
\hline Eu compraria um automóvel elétrico, pois emite menos gases de efeito estufa & & & & 8 \\
\hline $\begin{array}{l}\text { As baterias têm em sua composição metais pesados, que são tóxicos, podendo trazer danos se } \\
\text { descartados inadequadamente. }\end{array}$ & & & & 7 \\
\hline A queima do álcool emite menos gases poluentes na atmosfera. & & 11 & & 6 \\
\hline Percebi melhora na qualidade do ar na cidade de São Paulo. & 321 & & & 2 \\
\hline Converso com amigos vizinhos e parentes sobre questões ambientais. & 12 & & 1 & 3 \\
\hline O uso de automóveis prejudica a qualidade do ar. & & & & 7 \\
\hline Os seres humanos têm o direito de modificar o ambiente natural para atender às suas necessidades. & 22 & 1 & & 3 \\
\hline Total & 7422 & & 33 & \\
\hline
\end{tabular}

Fonte: Elaborado pelos autores (2017) 
Quanto ao comportamento ambiental, a Tabela $\mathbf{2}$ apresenta resultados muito parecidos no que diz respeito à motivação do uso de etanol, variando entre meio ambiente e preço. Mostra também que consumidores de combustíveis estão dispostos a aderir a um combustível menos poluente, entretanto, o fator monetário merece destaque, indicando que o modelo de negócios ideal deve conciliar preço, meio ambiente e medidas que incentivem o uso de transporte público.

Tabela 2: Quantidade de respostas por variável de comportamento ambiental onde 0 é discorda totalmente e 10 concorda totalmente.

\begin{tabular}{|c|c|c|c|}
\hline Variável de comportamento ambiental & \multicolumn{3}{|c|}{01234678910} \\
\hline Escolho abastecer meu veículo com etanol porque polui menos que a gasolina o meio ambiente. & & 11 & 6 \\
\hline Escolho abastecer meu veículo com etanol porque é mais barato. & 2 & 1 & 5 \\
\hline Utilizo transporte público para ajudar o meio ambiente. & 5 & 3 & \\
\hline Total & & 51 & \\
\hline
\end{tabular}

Fonte: Elaborado pelos autores (2017)

\section{CONCLUSÕES}

A partir dos autores utilizados na discussão do tema, é possível tecer algumas considerações finais que respondam ao objetivo do estudo, que foi de analisar a percepção e os comportamentos de compra de consumidores de combustíveis na região metropolitana de São Paulo-SP. Inicialmente, cabe destacar que apesar do tema "percepção e comportamento de consumidores de combustíveis" não ser recorrente na literatura, encontrou-se duas vertentes, a de consumo verde e comportamento pró-ambiental, que embasam em seu entendimento na liberdade de escolha.

Esta pesquisa aborda os fatores de saúde pública, mobilidade urbana, poluição ambiental e consumismo, pois no contexto atual, com o elevado número de motorização individual e decorrentes custos sociais, ambientais e econômicos, surgem novas discussões sobre normas e programas para a melhoria da qualidade de vida nas grandes cidades.

Buscou-se, com o presente estudo, verificar, por meio da conceituação de autores e de evidências de pesquisa empíricas, a possibilidade do consumo consciente de combustíveis. Tomou-se como pressuposto, que se os indivíduos têm consciência do impacto causado por sua escolha, voluntariamente tendem a aderir comportamentos conscientes de consumo (TONI et al., 2012).

No tocante aos objetivos específicos do trabalho, que era avaliar o impacto do perfil socioeconômico na escolha de combustíveis e a relação existente entre a percepção ambiental e o comportamento, foi observado que nesta amostra o nível socioeconômico não teve grande peso. Foi evidenciado que consumidores com diferente escolaridade e renda compartilham das mesmas opiniões, mas devido à quantidade reduzida de questionários não foi possível determinar correlação entre percepção e comportamento, declarado dos entrevistados. Obtivemos contribuições relevantes para novos estudos sobre motivações para o consumo de combustíveis menos agressivo ao meio ambiente. 
Como limitações do trabalho destaca-se a dificuldade em obter autorização dos proprietários ou responsáveis dos postos de gasolina, devido ao risco do trabalho em pista, o que impossibilitou coletar dados numa amostra maior de consumidores. Para pesquisas futuras sugerimos que a coleta dos dados seja realizada de forma online com o intuito de fortalecer a hipótese que a percepção impacta no comportamento e que está mais uma vez relacionada ao fator monetário.

\section{AGRADECIMENTO}

À Universidade Nove de Julho e a seu corpo docente que oportunizaram esta pesquisa. Ao gerente do auto posto Sagitário por conceder autorização para coletar os dados.

\section{REFERÊNCIAS}

ANDRÉS, Elena Fraj; SALINAS, Eva Martínez. Comportamiento del consumidor ecológico. ESIC Editorial, 2002.

BIODIESELBR, <https://www.biodieselbr.com/proalcool/flex-fuel/proalcool-flex-fuel.htm, $2006 . \quad$ Acesso em 23/06/2017.

BRASIL,<http://www.brasil.gov.br/meio-ambiente/2011/09/poluicao-do-ar-mata-pelo-menos-2-milhoes-depessoas-por-ano-no-mundo-diz-oms>, 2011. Acesso em 10/06/2017.

CASALI, Richelita do Rosario Brito et al. Responsabilidade Social do Consumidor: Conceituação e proposta de mensuração. 2011.

CETESB, <http://veicular.cetesb.sp.gov.br/>, 2013. Acesso em 10/06/2017.

CRUZ, M. M. L. Avaliação dos impactos de restrições ao trânsito de veículos. 2006. 2006. Tese de Doutorado. Dissertação (Mestrado em Transporte)-Engenharia Civil, Universidade Estadual de Campinas, Campinas.

DE TONI, Deonir; LARENTIS, Fabiano; MATTIA, Adilene. Consumo consciente, valor e lealdade em produtos ecologicamente corretos. Revista de Administração FACES Journal, v. 11, n. 3, 2012.

FERREIRA, Cássia Castro Martins; OLIVEIRA, Daiane Evangelista. Estimativa da poluição veicular e qualidade do ar nas principais vias do sistema viário da região central da cidade de juiz de fora-mg. Revista do Departamento de Geografia, n. spe, p. 98-114, 2016.

GIL, A. Métodos e técnicas de pesquisa social. São Paulo: Editora Atlas. 2006.

GONÇALVES, Roberto Birch; NASCIMENTO, Luis Felipe. Impacto da aplicação de técnicas de produção Limpa: Caso Pigozzi. Encontro Nacional de Engenharia de Produção, 1997.

GORNI, Patrícia Monteiro et al. Consciência ambiental e sua influência sobre o comportamento de compra com vistas à preocupação ambiental. Contextus-Revista Contemporânea de Economia e Gestão, v. 14, n. 1, p. 10-31, 2016.

MARTINS, L. A. A Temperatura do Ar em Juiz de Fora -MG: Influência do Sítio e da Estrutura Urbana. Dissertação (Mestrado em Geografia) -Departamento de Geografia, Instituto de Geociências e Ciências Exatas, UNESP -Rio Claro, Rio Claro p.168, 1996. 
DE OLIVEIRA, Paula Souza; DOS SANTOS, Adelice Oliveira. Consumo hedonista: impasses e contradições do consumidor pós-moderno para um planeta sustentável. Revista Educação, Tecnologia e Cultura-ETC, v. 13, n. 13, 2016.

PICKETT-BAKER, Josephine; OZAKI, Ritsuko. Pro-environmental products: marketing influence on consumer purchase decision. Journal of consumer marketing, v. 25, n. 5, p. 281-293, 2008.

PORTILHO, Fátima. Sustentabilidade ambiental, consumo e cidadania. Cortez, 2005.

DA SILVA, Jozionan Francisco et al. Mobilidade urbana e políticas públicas. Interface, v. 12, n. 1, 2016.

DA SILVA, Jozionan Francisco et al. Mobilidade urbana e políticas públicas. Interface, v. 12, n. 1, 2016.

DE QUEIROZ, Cecília Telma Alves Pontes et al. Diagnóstico da Consciência Ambiental dos Gestores: Eco-Atitudes e Consumo Sustentável em Campina Grande/PB-Brasil. Qualitas Revista Eletrônica, v. 8, n. 2, 2009.

STERN, Paul C. Information, incentives, and proenvironmental consumer behavior. Journal of Consumer Policy, v. 22, n. 4, p. 461-478, 1999.

STERN, Paul C. Toward a working definition of consumption for environmental research and policy. Environmentally significant consumption: Research directions, p. 12-35, 1997. 